\title{
Efeito de elevada dose de vitamina E no teste de tolerância à glicose em cordeiros com 28 dias
}

Débora Dias de Carvalho*, Priscilla Marques do Nascimento, Marcela Romanini Faria, Carolinne Broglio Deusdado,Aline Alberti Morgado, André Storti Martins, Ronald de Carvalho Neto, Marcel Zei Grunwald, Clara Satsuki Mori, Maria Claudia Araripe Sucupira

Faculdade de Medicina Veterinária e Zootecnia, Universidade de São Paulo (USP), São Paulo, SP, Brasil

*Autor correspondente

e-mail: deboracarvalho@usp.br

\section{Resumo}

As modificações hormonais que ocorrem durante a gestação refletem na saúde da ovelha e do cordeiro, especialmente quando há quebra da homeostase. Momento crítico ocorre no periparto, onde há reduzida ingestão de matéria seca e altas exigências nutricionais e de glicose pela a fêmea prenhe para a produção de leite e crescimento fetal. 0 mecanismo fisiológico que compensa esse aparente descompasso é a resistência insulínica periférica, que prioriza glicose para o feto e para a glândula mamária. Estudos recentes têm apontado a resistência à insulina como um dos importantes fatores envolvidos na patogenia da síntese aumentada de corpos cetônicos, tanto em ovinos, quanto em humanos; nestes últimos foi demonstrado que o desfavorável ambiente intrauterino de mulheres com diabetes gestacional proporcionou ao feto alterações metabólicas e maior morbidade perinatal. Há indícios que indivíduos com baixo status sérico de algumas vitaminas lipossolúveis, como a vitamina E, apresentam menor sensibilidade insulínica. Portanto, para verificar se o uso parenteral de alta dose de vitamina E (alfa-tocoferol), via intramuscular profunda (IM), teria efeito na sensibilidade insulínica do cordeiro, foram utilizados 14 cordeiros mestiços (Santa Inês x Dorper), distribuídos em dois grupos: grupo EE, constituído por cordeiros provenientes de ovelhas suplementadas com vitamina E (60UI/Kg, IM) no $100^{\circ}$ dia de gestação, os quais também receberam a mesma dose de vitamina E após 24 horas do nascimento; e grupo CC, formado por cordeiros oriundos de ovelhas suplementadas com veículo oleoso (IM) no $100^{\circ}$ dia de gestação e que, com 24 horas de vida, receberam o mesmo produto. Aos 28 dias de idade, os neonatos foram submetidos ao TTG. Após jejum de uma hora, receberam glicose 50\% (0,18g/Kg, IV) em bolus e amostras de sangue foram coletadas em 12 momentos $(-15,0,2,5,10,15,20,30,45,60,90,120$ minutos) para análise das concentrações plasmáticas de insulina e glicose. A área abaixo da curva (AUC) foi calculada para cada variável de cada animal no programa estatístico SAS (SAS Inst. Inc., Cary, NC). A insulina foi analisada no aparelho IMMULITE 200 
Immunoassay System ${ }^{\circledR}$ e a glicose no analisador bioquímico RANDOX ${ }^{\circledR}$ Daytona. Não foi observado efeito da suplementação com a vitamina E frente ao protocolo aqui utilizado para a AUC da glicose $(\mathrm{P}=0,457)$ e para a AUC da insulina ( $\mathrm{P}=0,203)$. Dada a importância da vitamina E como agente antioxidante e como suplemento na alimentação de ruminantes, constata-se a inevitabilidade de novos estudos para esclarecer a sua eficiência no periparto de ovelhas e cordeiros em relação à promoção da sensibilidade à insulina e suas interferências em outros parâmetros metabólicos tanto das ovelhas quanto dos cordeiros. 